\title{
ESTUDIO PILOTO: IMPORTANCIA DEL LIDERAZGO TRANSFORMACIONAL DEL DIRECTOR EN EL COMPROMISO DEL PROFESORADO Y DE LOS ESTUDIANTES EN UN CENTRO EDUCATIVO
}

\section{Natalia Zegarra Saldaña}

\section{RESUMEN}

Ante los nuevos retos impuestos por esta nueva era del conocimiento, el liderazgo educativo es percibido como un elemento clave para la mejora educativa. Este constructo se presenta como una meta y un medio para que otros aspectos sucedan. Se reconoce que la responsabilidad por la mejora educativa actual no debe ser una responsabilidad únicamente de los líderes educativos, sino ésta también debe recaer sobre los hombros de los docentes, quienes deben estar comprometidos con el cambio. La relación entre estas variables incidiría en el compromiso del estudiante con la escuela, y en el logro de mejores resultados académicos y de comportamiento.

El trabajo examina el efecto de las prácticas del liderazgo transformacional sobre las condiciones organizacionales, el compromiso de los profesores por el cambio y el compromiso de los estudiantes con el colegio. Este trabajo se realizó a partir de la combinación y adaptación de dos estudios realizados anteriormente, el primero en Canadá y el segundo en Hong Kong. Para establecer la relación entre las variables de estudio y determinar el efecto sobre el compromiso de los estudiantes, se realizó una encuesta piloto en un colegio privado de Cochabamba, Bolivia. Los datos permitieron explorar los efectos relativos de las prácticas del liderazgo transformacional sobre las variables seleccionadas, mismas que incluyeron las siguientes variables mediadoras: cultura del colegio, estrategias para el cambio, estructura del colegio y el entorno del colegio. Los resultados indican que existe una relación entre liderazgo transformacional y el compromiso del profesor por el cambio, así como con el compromiso de los estudiantes.

Palabras Clave: Liderazgo Escolar, Liderazgo Transformacional, Compromiso Organizacional del Profesor, compromiso del Estudiante.

DOI: 10.23881/idupbo.019.2-10e 